\title{
A Study of Accounting Outsourcing Decision: The Case of Malaysian SMEs
}

\author{
Gholamreza Zandi ${ }^{1}$, Thee Kok Chuan ${ }^{2}$ \& Shaheen Mansori ${ }^{3}$ \\ ${ }^{1}$ Universiti Kuala Lumpur Business School, Malaysia \\ ${ }^{2}$ Graduate School of Business, SEGi University, Malaysia \\ ${ }^{3}$ Malaysian University of Science and Technology (MUST), Malaysia \\ Correspondence: Gholamreza Zandi, Universiti Kuala Lumpur Business School, Malaysia.
}

Received: April 30, 2019

Accepted: May 30, 2019

Online Published: June 10, 2019

doi:10.5430/ijfr.v10n5p153

URL: https://doi.org/10.5430/ijfr.v10n5p153

\begin{abstract}
Nowadays the costs of doing business have been increased and become more competitive than before. Hence, many organizations have been thinking to outsource activities which are not the core competence of the organization such as finance and accounting, information technology, human resources, and any other back-office activities. This research provides an understanding of the factors influencing of the organization intends to outsource the finance and accounting activities decision for the Small and Medium Enterprises (SMEs) in Malaysia. The research uses a qualitative exploratory and explanatory method. The qualitative data collected via individual interviews with Malaysia Small and Medium Enterprises' decision makers and a higher level of management group which comprises of individual or organizations. The results suggest that Malaysian SMEs would shorten their decision-making process to make a business process outsource if they can see the success story of other organizations.
\end{abstract}

Keywords: outsourcing, acceptability, confidentiality, accessibility, resources, efficiency information technology, organization intention

\section{Introduction}

Finance and accounting outsourcing means passing some of the finance and accounting duties to third-party providers for the benefits of scare skills, cutting the costs of doing business or gaining more competitiveness (Financial Services Authority, 2005).

The prior research on the perceived benefits of business process outsourcing (Heiko Gewald, 2010; Brown, \& Ozar 2018) shows that perceived benefits, cost advantages, core competencies, specialized resources, and quality improvement, have a positive relationship towards the intention to increase the level of business process outsourcing.

Recently the finance and accounting outsourcing is growing rapidly and Asia becomes a populating destination for the business processes relocation. Malaysia SMEs shall be capitalized these opportunities to further cutting the costs of doing business and further increased the competitions, thereafter the finance and accounting outsource service providers will be capitalized the Malaysia SMEs market too. Mostly the decision of outsourcing is due to the cost cuttings, other specific factors, and competition. The research on Malaysia had studied on the transaction cost in finance and accounting offshore outsourcing and shown that the potential transaction cost exists between clients and vendors: contact, contract, and control (Aini Aman et al., 2012; Bin Jiang et al., 2006; Bugu \& Yucheng 2018).

Therefore, there are need to study and understand the factors may influence the intention of finance and accounting outsourcing decision in Malaysia SMEs, from there to improve the outsourcing effects on firms' operational performance. The factors influencing the intention of finance and accounting outsourcing decision in Malaysia SMEs are Acceptability, Confidentiality, Accessibility, Resources, and Efficiency - A CARE.

For the Malaysia SMEs, this research paper provides in-depth information to consider before they have the intention to outsource the finance and accounting duties to the third party. The effects and influences between outsourcing intention and Theory of Planned Behaviour (TPB) and transaction costs economics (TCE) will be as a guideline for the Malaysia SMEs and outsourcing providers. When the Malaysia SMEs examine the factors before outsourcing the 
finance and accounting of the organization, the risk and perceived benefits of the business process outsourcing will be improved.

Moreover, the effects of the operational performance of the Malaysia SMEs will also be improved if the SMEs examine the factors before outsourcing the finance and accounting duties to the third party. The outsourcing providers will benefit from this research too as the outsourcing providers may closely examine the factors may influencing their potential clients' intention to outsource the finance and accounting duties. Therefore, both of the services providers and the SMEs themselves could be enjoying the success of the finance and accounting outsourcing in consideration of budget, scare of resources and efficiency.

\section{Literature Review}

The Malaysia SMEs make an all range of outsourcing and the decision for the intention of finance and accounting outsourcing are review for this research. Therefore the literature review will be reviewed the theories, subject of research, the decision of intention of outsourcing, Malaysia outsource industry, the definition of Malaysia SMEs and finally the factors of the intention of finance and accounting outsourcing for Malaysia SMEs.

\subsection{Basic Concept}

\subsubsection{Outsourcing Definition and Background}

Busi and Mclvor (2008), introduce that outsourcing and supply chain management search in the internal will resulted in roughly 55 million pages and become one of the fastest developing disciplines of the past century. The original theoretical underpinning of current outsourcing research from the supply chain management or manufacturing would arguably on "make-or-buy" and the other from the service providers would see it as a revolutionary trend. Hence, outsourcing can be explained based on the Transaction Costs Theory (Coase, 1937; Williamson, 1975, 1985).

From this research, Marco Busi and Ronan Mclvor studied and clarified the current research is process focus against non-production related. Due to the developing of communication and information technologies, the business processes services outsourcing for human resources, information technology, R\&D services, and finance and accounting services has grown and transferred the responsibility of the whole functions internally to external service providers.

Weimer and Seuring (2008) points out the key research questions that investigated: "Why should a company outsource?", "What should be outsourced?", "How should the outsourcing relationship contract be managed?", and "What are the main success factors with outsourcing?" (See also De Boer et al., 2006; Jiang et al., 2006; Harland et al., 2008; Canh \& Liem 2018). The research on outsourcing to date has been used survey or case study research methodologies.

\subsubsection{The Decision of Intention to Outsource}

According to Murphy et al. (2012) literatures point out that the business processes' decision to outsource was different from other purchasing decision. He pointed Gilley et al., (2004) research cited that the outsourcing process is the strategic bent that different from other resource procurement activities. This is because outsourcing had replaced the internal activities with the external and discontinuation of internal operations to the outside of the organization suppliers (Ahmed, Abdul Majid, Mohd Zin, Phulpoto \& Umrani, 2016; Obay, 2018).

Hence the factors of influencing the intention of finance and accounting outsourcing in Malaysia SMEs must be studied by the decision makers and examining the factors before. Once the factors positively react, then the intention of finance and accounting outsourcing will be more likelihood reacted positively. This research will be helping both sides, the decision makers and outsourcing service providers, as a guideline before that outsourcing their finance and accounting or proposed a proposal to the organization intends to outsourcing their finance and accounting function to outside the organization.

The strategic context of the decision was also another important element to understand before the small organization outsourcing behavior. All the decision of the small organization was decided by the leader of the organization, therefore understanding the leaders' objective will improve the results of the decision. Murphy et. al. (2012) reviewed the firm growth theory and integrates the theoretical approaches. Small business operation and entrepreneurship activities are very focused on firm growth (Cavico, et.al 2018; Murphy, 2012; Shane and Venkataraman, 2000; Venkataraman, 1997). Due to the small organization lack of resources, therefore they will alertness to external opportunities or adjusting the internal organization structure and resources (Jermsittiparsert et al., 2016; Obi \& Okekeokosisi 2018). From this point of view, we may understand that the decision makers for the 
Malaysian SMEs outsourcing the finance and accounting is the leaders, most of the case in Malaysia SMEs is the Directors themselves.

\subsubsection{Malaysia Outsourcing Industry}

According to the case study of Aman et. al (2012), services sectors included shares services and outsourcing and IT services, become the significant growth contributors for the Malaysia economy. Currently, these services sectors were growing at double the 15 percent global growth. This industry will expect to employ 300,000 employees, if it continues to grow at the rate as expected, by then 40 to 45 percent of growth will be targeted (Bernama, 2010). According to MDES, 185 shared service outsourcing companies in Malaysia, 16 percent of the companies are focusing on finance and accounting activities and offering 22,800 out of 47,300 jobs offered in 2010 (Haseeb, Abidin, Hye \& Hartani, 2018; Bernama, 2010; Chan, 2018). In the reported particular year, the finance and accounting shared services outsourcing industry contributes to 36 percent of Malaysia total export and 27 percent of Malaysia total revenues (Bernama, 2010; Obiekwe 2018). Therefore, AT Kearney (2004, 2005, 2007, and 2009) Offshore Location Attractiveness Index has ranked Malaysia as the world's third most attractive outsourcing location.

\subsection{Definition for Malaysia SMEs}

Malaysia has applied a common definition of small and medium enterprises (SMEs) to identify SMEs in the various sectors and subsectors. Hence, the Malaysians government had given the Small and Medium Enterprise Corporation Malaysia (SME Corp. Malaysia) to categorize the Malaysia SMEs into three (3) type based on the annual sales turnover or the number of full-time employees. The 3 types of the SMEs are Micro Enterprise, Small Enterprise, and Medium Enterprise. For the manufacturing and agro-based industry, the Micro, Small and Medium enterprise based on the annual sales turnover for is less than RM250, 000, RM250, 000 to RM10 millions and RM10 millions to RM25 millions respectively. If based on the number of full-time employees is less than five, from 5 to 50 and 51 to 150 respectively.

For the services, primary agriculture, ICT and services, the annual sales turnover for Micro, Small and Medium would be less than RM200, 000, from RM200, 000 to RM1 million and from RM1 million to RM5 millions respectively. If based on the number of full-time employees than it would be less than 5,5 to 19 and 20 to 50 respectively.

The research aims to examine the two major theories, Theory of Planned Behavior (TPB) and Transaction Costs Economics (TCE). The TPB is an analysis of the attitude of the consumers and perceived behavioral control for the purchasing intention of outsourcing for the Malaysia SMEs. On the other hand, the TCE has been explained in the purchase of management advisory service research by Kent (2011).

Ajzen, 2002 proposed the TPB consist of three independent determinants of behavior intention: attitude, subjective norms and perceived behavioral control. When the intention of the purchaser to perform a certain behavior is strong, then the likelihood of the behavior been performed is likely (Golnaz Rezai, 2011; Chang, 2017).

Ajzen, 2002 proposed the TPB consist of three independent determinants of behavior intention: attitude, subjective norms and perceived behavioral control. When the intention of the purchaser to perform a certain behavior is strong, then the likelihood of the behavior been performed is likely (Golnaz Rezai, 2011; Pamela Kent, 2011; Chi, 2018). Hence, the factors of acceptability, confidentiality, and accessibility are included in this study for further discussion.

\subsubsection{Acceptability}

The decision makers of the organization's intention to outsource the business processes involved are operationalized intention. According to Wong (2005), "the likelihood of offshoring an IT activity" for the intention to outsource offshore is operationalized. Current studies showed that, if a positive likelihood to outsource the IT application to a foreign country, then it shows an encouragement to transfer the activity offshore. Therefore, from this research, it created the similarity for the Malaysia SMEs' intention to outsource finance and accounting. A literature review has shown that Wong (2005) had developed three items of the definition of "the intention to offshore". The definition developed as:

- Over the next two (2) years, what is the likelihood that y our organization will offshore the IT activity to [a county name]?

- How confident are you that your organization will offshore the IT activity to within the next two (2) years?

- What is the probability that you will offshore the IT activity to [a country name]? 
Theory of Planned Behaviour (TPB) serves as a strong theoretical foundation which also consistent with previous research. The three factors from the TPB are clearly demonstrated in the two models examined - "perceived behavioral control", "subjective norm" and "attitude towards offshoring" -in predicting the "intention of offshoring".

\subsubsection{Confidentiality}

The secret of the information been kept by the outsourcing providers will be also another factor could influence the organization decision of outsourcing of FA. This is because the data collected by the outsourcing providers all are highly confidential and classified as the top secret of the organization. The data included the suppliers and customers listing and prices. Therefore, for the top secret of the organization will only provide to the higher level personnel of the outsourcing providers will encourage the organization to outsource.

\subsubsection{Accessibility}

Time is money may answer to the independent variables for accessibility. This is because the data and information of the finance and accounting are always required by the CEO of the organization or the leaders of the organization anytime. As the data and information of the finance and accounting were always required by the leaders or CEO of the organization to make a strategic decision.

According to Hesketh (2008), the amount of time and the financial resource needed to make the service delivery decision. Moreover, most of the organization had been through this process a few times when outsourced their human resources or/and finance and accounting decision. Normally the organization will decide to attempt the own change program, follow by moved to shared service models and finally outsourced their relevant function. AT\&T, Lucent Technologies, the BBC and HP had utilized this incremental approach to service delivery strategy. This approach also outlays the safety-first approach to service delivery. Since the time is money, then the technologies would be accurate to identify the outsourcing is technology-driven-strategy. This is due to the technology sits in the middle of the outsourcing sector. Technology has a positive relationship with accessibility (Chiang, \& Tzou 2018).

Meaning that the higher of the technology in place for the outsource service providers, the factors of accessibility of the dependent variable is fulfilled. This is because the leaders/CEO of the organization required the data information of finance and accounting, the technology may improve the time or the speed of accessibility of information.

\subsubsection{Resources}

The Tate (2006) cited that outsourcing an attractive option as the wages are a higher cost of administrative performance cost and no physical goods hands. Therefore all the organization tries the possibility to reduce the costs by shifting the jobs to the lower range of wages country (Farrell, 2004). Moreover, to outsource the business processes to a third party offshore will reduce the staff costs and retain the marketplace advantage of the organization. Cost versus quality had been examined by Tate (2006), the cost reduction is the main motivation of offshore outsourcing.

According to Kent (2006), the highest of the diversity of the external environment uncertainty was positively encourages the organization to outsource the management advisory services (Klein et al., 1990; Chima \& Kasim 2018). Meaning to say that, when the organization with the limited internal resources or multiple levels of subsidiaries or operation within the organization, then the factors may influencing the decision makers to outsource the finance and accounting function to a third party will be high possibility than internally generated.

\subsubsection{Efficiency}

In addition, Tate (2006) shown that the service quality received by the organization from the outsourcing service providers is better or equal to the organization self-provided. This was been proofed that the organization that offshore outsourcing to India was received better or equal quality form the outsource service providers. Transaction Costs Economics (TCE) compliments agency theory and gives a meaning of whether the transactions are the good coordinated in the other governance structure or market within the organization (Jensen, 1983; Williamson, 1988). According to Kent (2011), TCE and agency theory are similar as based on adopting an efficient contract arrangement for profitability oriental organization, managerial discretion and propose the company directors arise endogenously. Hence, the independent variables of resources and efficiency could be supported. Moreover, the Patrick J.Murphy et al., 2012 literature review shows that the outsourcing of business process enhanced the organization performance due to increase organization efficiency through the management focuses on the core competencies and reduction of cost (Gulbrandsen et al., 2009; McNally and Griffin, 2004). 


\section{Research Methodology}

Using the in-depth interviews method, to be arranged with individual or group of the decision maker of financial and accounting outsourcing services, most of the case in Malaysia SMEs is the Directors themselves or the business owner. The respondents participated in the interviews are selected from nigh companies three from each Micro, Small and Medium organization as defined by the Malaysian Government. The interview questionnaires were only available in the English form. However, the interviewers translated questions into respondent familiar languages, Malay or Chinese, when requested by the respondent.

\section{Findings and Discussions}

\subsection{Acceptability}

In general conclusion, Malaysian SMEs agreed that Financial Accounting Outsourcing practices are generally acceptable and adoptable internally and externally with business operations and practices. Participated SMEs believe that partial outsourcing of the non-core operational activities could provide better quality, overall beneficial and adaptable for internal processes. However, Malaysian SMEs required the Financial Accounting Outsource service provider to have a collaborative strategy to work with the Malaysian SMEs, suiting to organizational requirements, cultures and operational arrangement.

In addition, based on Malaysian SMEs who have frequent trading with foreign and overseas entities, the organization management hinted for the local Malaysian Financial Accounting Outsourcing providers to revise, upgrade and adjust their conventional accounting method to match and cope with the overseas trading business model. Malaysian Financial Accounting Outsourcing provider is expected to level up their play flew to embedded with technology such as cloud base software, storage, and other relevant technology.

\subsection{Confidentiality}

The finding shows that the majority of the Malaysian SMEs are less demanding on the confidentiality of data as long as the information is being circulated among the professional firm itself. Instead, Malaysian SMEs prefer and usually request the Financial Accounting Outsourcing provider to communicate, discuss and liaise directly with for the SMEs compliance services, such as Audit, Taxation, and Secretarial services. Based on the finding, most of the respondent are comfortable to disclose their financial data and information to the said compliance services providers and they expect the Financial Accounting Services provider to able to deliver related documents and information requested.

However, for SMEs which involve sensitive trade secrets, especially related to their source of supply and customer base, the participant showed more concern on the security and safekeeping of their company trade secrets. These SMEs highlighted repetitively the circulation of information are only allowed to be used within the group of Financial Accounting Outsourcing providers if such case involves other compliance services such as Audit, Taxation, and Secretarial services.

\subsection{Accessibility}

Overall, small scale Malaysian SMEs demand lesser attention and more tolerable towards the accessibility to their outsourcing providers with grace time of two days. However, for SMEs in a larger size, they often required high attention and quick respond from the Financial Accounting Outsourcing providers. The reason is found in this research are mainly because of prompt decision making required for the issues and matters. In line with the statement of Hesketh (2008), this research discovers Malaysian SMEs are expecting Local financial accounting outsourcing service provider to invest into technology especially that directly relate to the relationship with accessibility time taken by these SMEs. This is especially applicable to cross-border and geographical SMEs business in Malaysia.

\subsection{Resources Management}

Refer to Tate (2006) cited that outsourcing an attractive option as the wages are a higher cost of administrative performance cost, all respondents from this research agreed that Financial Accounting outsourcing overall helped in expenditure reductions of the business Operation. Cost savings resulted from the general overhead of maintaining finance department, qualified accountants remuneration, investment in accounting software and license renewal, management time and effort in maintaining, training and developing the given by this outsourcer as qualified accountant team with the fraction of the price paid to hire an in-house qualified accountant or finance department. 


\subsection{Efficiency}

This research concludes that efficiency and effectiveness resulted from Financial Accounting outsourcing services are value added on top of the Malaysian SMEs expectation. Based on the collaboration model discussed from Acceptability, most of the respondent agreed that organization enhance the business operations efficiency and effectiveness resulting in less management time and focus being diverted to Financial Accounting management matter. Through Financial Accounting Outsourcing practices, these Malaysian SMEs experience technical knowledge development and enhancement from the support provided by the outsourcing team. These SMEs also highlighted that with this knowledge and support, the SMEs organization able to realign, revamp, revise and adjust existing business strategy .implementation and direction. Functions and capabilities of accounting personnel to be performing in the organization. Most respondents concluded that with the cost paid for Financial Accounting Outsourcing, it generates more values to the organization than maintaining-house finance department due to the support.

Apart from the five factors being discussed extensively in the study, the research also discovers another two important elements which are the synergy effect generated from financial accounting outsourcing. Throughout the whole interview session with all even participants, they have highlighted that none of the element is independent on its own, but they are interrelated to each other. The five factors are interlocking and neither of it dominates the other factor in consideration.

In addition, the synergy effect doesn't really only comes from this five-factor but also included the flexibility of accounting outsourcing service provider's functionality. As discussed in the earlier chapter, all respondent highlighted that they prefer to have a business model that specified and suits to their business operation methodology such as internet and cloud base, different personal contact and accessibility, require customization of services scope and expecting synergy created by outsourcing multiple business functions to single entity yet the group of company able to communicate seamlessly among the interdepartmental, yet ensuring accurate information flows within the providers themselves.

In overall, Malaysian SMEs does not only seek for regular book-keeping and accounting services to be handled by the outsourcing team, yet they are searching for a business partner to grow together with SMEs business, able to support, irrigate, cultivate and evolve together in the business environment. SMEs required help and assistance more than regular services for compliance's sake, but to be prepared, develop, eager to soar high via the supports from accounting outsourcing providers.

The finding of this research shown guidelines, critical criteria and Key Success Factor to local accounting providers on how to improve and increase their competitive advantages and ensure business sustainability in such competitive wide market. Most of the participants of the research shared and explained their point-of-view, assessment, and considerations prior they decide to outsource the services to specific accounting providers.

With this information, accounting outsourcing providers could revamp their business strategy or even a business process to suits and meet the requirement and expectation of SMEs business better. In terms of SMEs business owner angle, this research displayed information and thoughts of other SMEs Business from different sizes and background, enable to them have a better understanding of other business best practices available in the market. With so, they could explore further in future business collaboration with the outsourcing provider in order to generate operation synergy especially to grow the business share yet ensure the good looking bottom of the business. With their own business strength, they could make use of the support from the outsourcing party and developed a strategy to achieve greater success.

\section{References}

Ahmed, U., Abdul Majid, A. H., Mohd Zin, M. L., Phulpoto, W., \& Umrani, W. A. (2016). Role and impact of reward and accountability on training transfer. Business and Economics Journal, 7(1), 1-6.

Aman, A., Noradiva, H., Amiruddin, R., \& Maelah, R. (2012). Transaction costs in fiancé and accounting offshore outsourcing: a case of Malaysia. Strategic Outsourcing: An International Journal, 5(1). https://doi.org/10.1108/17538291211221960

Barrar, P., Wood, D., Jones, J., \& Vedovato, M. (2002). The efficiency of accounting service provision. Business Process Management Journal, 8(3). https://doi.org/10.1108/14637150210428925

Brown, E. D., \& Ozar, V. (2018). Effect of Poultry Production on Agricultural Production in Nigeria. Economy, 5(1), 8-16. https://doi.org/10.20448/journal.502.2018.51.8.16 
Bugu, Z. Y., \& Yucheng, H. (2018). An Empirical Analysis of the Factors Affecting the Profitability of China's Agricultural Listed Companies under the Background of Agricultural Modernization. International Journal of Applied Economics, Finance and Accounting, 2(1), 19-26. https://doi.org/10.33094/8.2017.2018.21.19.26

Busi, M. (2008). Setting the outsourcing research agenda: the top-10 most urgent outsourcing areas. Strategic Outsourcing: An International Journal, 1(3). https://doi.org/10.1108/17538290810915263

Canh, N. T., \& Liem, N. T. (2018). Applying Panel Dynamic OLS and Panel VECM to Estimate the Relationship between Public Investment, Private Investment and Economic Growth in Developing Asian Countries. Global Journal of Social Sciences Studies, 4(2), 115-126. https://doi.org/10.20448/807.4.2.115.126

Cavico, F. J., Mujtaba, B. G., Muffler, S., Samuel, M., \& Polito, N. M. (2018). Manufacturer, Supermarket, and Grocer Liability for Contaminated Food and Beverages due to Negligence, Warranty, and Liability Laws. Economy, 5(1), 17-39. https://doi.org/10.20448/journal.502.2018.51.17.39

Chan, J. (2018). A Critical Study of Kong Girls Phenomenon in Hongkong Society. Humanities \& Social Sciences Reviews, 6(1), 25-28. https://doi.org/10.18510/hssr.2018.615

Chang, P. (2017). The Importance Performance Analysis of Taiwan tourism mobile marketing. Journal of Tourism Management Research, 4(1), 12-16. https://doi.org/10.18488/journal.31.2017.41.12.16

Chi, Y. N. (2018). Scenario Economic Impact Analysis of Offshore Fishing Tournaments in Ocean City. International Journal of Business, Economics and Management, 5(5), 128-134. https://doi.org/10.18488/journal.62.2018.55.128.134

Chiang, P.-M., \& Tzou, H.-I. (2018). The Application Of Differential Person Functioning On The Science Literacy Of Taiwan Pisa 2015. Humanities \& Social Sciences Reviews, 6(1), 8-13. https://doi.org/10.18510/hssr.2018.612

Chima, P., \& Kasim, U. (2018). Public-private partnership as a strategy for e-governance funding in Africa: The gains and the pains. International Journal of Public Policy and Administration Research, 5(2), 37-47. https://doi.org/10.18488/journal.74.2018.52.37.47

Companies Commission of Malaysia. (2013). Publication - Statistic. Retrieved 1 August 2013, from http://www.ssm.com.my/en/statistic-total-business-companies

Crossan, F. (2003). Research philosophy; towards an understanding. Nurse Researcher Journal, 11(1). https://doi.org/10.7748/nr2003.10.11.1.46.c5914

Gewald, H. (2010). The perceived benefits of business process outsourcing: an empirical study of the German banking industry. Strategic Outsouring: An international Journal, 3(2). https://doi.org/10.1108/17538291011060321

Haseeb, M., Abidin, I. S. Z., Hye, Q. M. A., \& Hartani, N. H. (2018). The Impact of Renewable Energy on Economic Well-Being of Malaysia: Fresh Evidence from Auto Regressive Distributed Lag Bound Testing Approach. International Journal of Energy Economics and Policy, 9(1), 269-275.

Hesketh, A. (2008). Industry insight: Should it stay or should it go? Examining the shared services or outsourcing decision. Strategic Outsourcing: An International Journal, 1(2). https://doi.org/10.1108/17538290810897165

Hox, J. J., \& Boeije, H. R. (2005). Data collection, primary vs secondary. Encyclopedia of Social Measurement, 1, 593-599. https://doi.org/10.1016/B0-12-369398-5/00041-4

Jermsittiparsert, K., Sriyakul, T., Pamornmast, C., Rodboonsong, S., Boonprong, W., Sangperm, N., ... \& Maneechote, K. (2016). A Comparative Study of the Administration of Primary Education between the Provincial Administration Organisation and the Office of the Basic Education Commission in Thailand. The Social Sciences, 11(21), 5104-5110.

Jiang, B., Frazier, G. V., \& Prater, E. L. (2006). Outsouring effects on firms' operational performance: an empirical study. International Journal of Operations \& Production Management, 26(12). https://doi.org/10.1108/01443570610710551

Kent, P. (2011). The decision to outsource management advisory services. Managerial Auditing Journal, 26(8). https://doi.org/10.1108/02686901111161331

Lacity, M. C., Willcocks, L. P., \& Rottman, J. W. (2008). Global outsourcing of back office services: lessons, trends, and enduring challenges. Strategic Outsourcing: An International Journal, $1(1)$. https://doi.org/10.1108/17538290810857457 
Murphy, P. J., Wu, Z. H., Welsch, H., Heiser, D. R., Young, S. T., \& Jiang, B. (2012). Small firm entrepreneurial outsourcing: traditional problems, nontraditional solutions. Strategic Outsouring: An International Journal, 5(3). https://doi.org/10.1108/17538291211291774

Obay, L. A. (2018). The Capital Structure Choice: Evidence of Debt Maturity Substitution By GCC Firms. Asian Economic and Financial Review, 8(11), 1298-1312. https://doi.org/10.18488/journal.aefr.2018.811.1298.1312

Obi, M. N., \& Okekeokosisi, J. (2018). Extent of Implementation of National Entrepreneurship Curriculum in Tertiary Institutions as Perceived by Educators. American Journal of Education and Learning, 3(2), 108-115. https://doi.org/10.20448/804.3.2.108.115

Obiekwe, O. (2018). Human Capital Development and Organizational Survival: A Theoretical Review. International Journal of Management and Sustainability, 7(4), 194-203. https://doi.org/10.18488/journal.11.2018.74.194.203

Small and Medium enterprises Corporation Malaysia. (2013). Definition of SME. Reterieved 15 July 2013, from http://www.smecorp.gov.my/vn2/node/37

Tate, W. L. (2006). Purchasing outsourcing services from offshore suppliers. ProQuest Dissertations and Theses.

Wikibooks. (2013). Research Methods and Types of Research. Reterieved 24 July 2013, from http://en.wikibooks.org/wiki/Research_Methods/Types_of_Research

William. (2006). Deduction and induction. Reterieved 25th July 2013, from http://www.socialresearchmethods.net/kb/dedind.php

Wong, S. F. (2005). Examining factors influencing offshore outsourcing deceision. ProQuest Dissertations and Theses. 